\author{
Eliona Bimbashi Kulluri ${ }^{1}$, Marsela Allmuça ${ }^{2}$ \\ ${ }^{1}$ Department of Social Work and Policies/Faculty of Social Sciences/ University \\ of Tirana, elakulluri@yahoo.com \\ ${ }^{2}$ National Association of Social Workers-Albania,
}

\title{
CHILDREN AT RISK: SOCIAL POLICIES AND SERVICES AND THEIR IMPACT IN ALBANIA
}

UDK:364-72-058.17-053.2(496.5)

\begin{abstract}
Albania society has experienced a prolonged transition which is accompanied with substantial changes that have caused effects on families and especially children's lives. Groups of children at risk of social exclusion in Albania are: working and street children, children in conflict with law, poor children, Roma children, children who are subjected to violence and trafficking, children involved in the phenomenon of the blood feud, children with disabilities and children living in rural areas.

This categories shares very difficult experiences such as living in minimal conditions, suffer lack of access to key services such as lack of health services, very low attendance and lack of access to educational institutions. These consequences associate with lack or inadequacy of appropriate service provision and lack of coordination between the responsible structures.

The purpose of this study is to analyze the situation of children at risk in Albania, policies and services for this category, their impact as well. For the realization of the study are used methods of secondary data analysis combined with qualitative data provided through semi-structured interviews with key persons in different decision-making level, and focus groups with children at risk.
\end{abstract}


Key findings are related with lack of policies to address the prevention, protection, assisted voluntary return, repatriation and reintegration of trafficked children; gaps in the implementation of the National Action Plan to Combat Trafficking in Children; lack of coordination between institutions and services; services and programs at central and local level for children as Children Protection Units are not spread across all the territory; there is a reduction in the number of residential and day services and increase of community once, etc.

Research findings conclude with the need for improved social care legislation and creating of suitable legal acts, which emphasizes the role of stakeholders in supporting children; Foreseen policies that address the prevention, protection, assisted voluntary return, repatriation and reintegration of trafficked children; to include the elimination of child labour in general policies and national programs; creating multi-sectoral mechanisms to identify victims of trafficking, especially trafficked children, etc.

Keywords: children at risk, needs, social services, social care, social policies.

\section{Introduction}

Children who face the risk of social exclusion in Albania live in minimal living conditions, suffer lack of access to key services such as water, electricity, road infrastructure, sewerage, water supply, health services, they have low attendance and lack of access to educational institutions. Among the groups at risk of social exclusion are mainly working street children, children in conflict with the law, Roma children, children who are subject of violence and trafficking, children involved in the phenomenon of the blood feud, children with disabilities and children living in rural areas. Children as trafficking contingent are mainly from families with economic and social problems characterized by domestic violence, abuse, exploitation and / or neglect. They come from poor families that put children at work, at the age of education. 
Policies, that address the prevention, protection, assisted voluntary return, repatriation and reintegration of trafficked children, need to implement the National Action Plan to Combat Trafficking in Children. Also, the lack of multi-sectorial mechanisms to identify trafficked children requires coordination between institutions and stakeholders working in the field of child trafficking.

\section{Methodology}

Aim of study/research: The purpose of this study is to analyze the situation of children at risk in Albania, policies and services for this category, their impact as well.

\section{Research topics:}

- The situation of children at risk;

- Assessment of the legislative and institutional framework;

- Evaluation of implementation of policies and programs on children at risk.

\section{Research questions:}

1. Which are the services that address the needs of the children at risk?

2. How much effective are the actual services for the children at risk?

3. Which is the impact of the service to the children at risk life?

\section{Research methods}

The study is based on a mixed methodology that includes secondary data analysis combined with qualitative methods. To enhance the validity of the findings, different sources were used to obtain the data analysis in the present report.

\section{a) Secondary sources}

The secondary resources include official data, as well as studies, surveys and annual and periodic reports of NGOs, international organizations and research entities in related fields. Data and information 
were gathered from MSWY, INSTAT (main source of official statistics), and other governmental institutions such as IPH, HII, SII, NES, SSS.

\section{b) Qualitative Data}

In order to carry out this study were used semi-structured interviews with key persons in different decision-making level (20 semistructured interviews in central, regional and local institution representatives) and focus groups with children (3 focus groups with children with social problems).

\section{Semi-structured interviews}

Participants were selected to ensure representation of groups with different social, economic, cultural and professional status, as well as geographic representation of the country taking in account the density of each target group at the level of municipality and commune (first-level LGU). For this purpose, a list of items to be discussed and instructions to guide discussions were designed in accordance with the specificities of each cluster of issues. A representative sample of in-depth semi-structured interviews was implemented with central, regional and local government representatives, as follows: a) policy and decision makers at central government level, b) policy makers and coordinators of social programs at the regional level (second-level LGU, i.e. regional councils), c) providers of services at the local level (first-level LGUS, i.e. municipalities and communes).

The sampling took account also of the urban/rural division in interviews held with representatives of administrative staff and focus groups in LGUs selected for their marginalized groups.

\section{Focus Groups}

Each focus group was composed of 6-8 participants with working street children, children in conflict with the law, children involved in the phenomenon of the blood feud, children with disabilities and children who live in rural areas. 


\section{DATA ANALYSIS}

\section{Legislative and institutional framework}

The review of policy documents and legislation framework on children at risk shows that commitment to the protection for this target group through legislative and institutional reforms is expressed clearly at the policy level, notably in the Albanian government's program for 20092013 (MIE, 2009), as well through legislative measures in the protection of children's rights to conclude with the adoption of the Law on "Protection of the Rights of children" (Low No. 10347, 2010) and with 5 by laws that meet the necessary legal framework for the protection of children's rights (March, 2012).

In the framework of coordination and harmonization of social protection and involvement of children, is estimated the draft "Plan of Action for Children 2012 - 2015" (PAC), which aims at strengthening the institutional structures that are set up to monitor and report the implementation of children's rights and promote the development of inclusive policies. In 2012-2015 PAC is envisaged to set up the mechanism at local level in cooperation with CPU and Labour Inspectorate to identify the worst jobs for children.

It is estimated that the National Strategy for Social Inclusion (NSSI) has paid special attention to the dynamics of the development of children at risk of social exclusion policy and progress towards achieving the rights to this target group. NSSI objectives for children at risk of social exclusion are in full compliance with the "Sector Strategy for Children" and "National Action Plan 2012 - 2015" (MSWY,2011). It is evaluated as relevant, the fact that child protection in these documents is not considered only as a preventive action, but as an action that focuses also on providing services until the child is no longer at risk.

The objectives stated in NSSI have been very important for the institutionalization of free legal assistance to vulnerable groups. Thus, to the Albanian Government has been proposed the definition of a legal framework and Legal Assistance Strategy for civil cases, approved by Law no. 10039, dated on 22.12.2008 "On legal aid" (Ministry of Justice, 
2013). Obstacles encountered about free legal services are related to the length of the proceedings and in some cases the quality of service provided by lawyers. For this purpose, the Ministry of Justice has taken the initiative to reform the Criminal Procedure Code, Civil Procedure Code, and the Law "On the profession of lawyer, Republic of Albania".

The Ministry of Justice is in process of drafting the "Strategy for Juvenile Justice" together with its Action Plan, assisted by UNICEF, which will contain concrete objectives and measures measurable in time and quality to be undertaken by each institution involved in this process.

"With regard to the procedures for the treatment of minors, the Ministry of Justice is designing a strategy for juveniles, but also in the Action Plan for Children which is expressed in three goals, where one of these ensure adequate protection of children up to 14 years in conflict with law, that today poses a problem since there is no law against it in the Albanian legislation. However, the expectation is positive after the time limit is set for 2015 and currently is in the process of implementation of educational measures for children at this age. For children up to 14 years old are taken only educational measures and here lies the gap in legislation. (Key informant interviews: Ministry of Justice)

Regarding to the institutional framework for addressing the issues of children at risk, at the Ministry of Social Welfare and Youth (MSWY) is established the National Agency for Child Protection which has the mission of monitoring the implementation of the law and government programs for children.

In addition, the establishment of Child Protection Units in the Municipalities and Communes and Unit of Children's Rights at the regional level is a positive step in the protection of children's rights and the implementation of measures that encourage meeting the needs of children at risk of social exclusion. There are currently set up $11 \mathrm{CRU}$ and $28 \mathrm{CPU}$ at the regional and municipality level. (MSWY/Official data, 2013) Currently, these units are limited in terms of territorial expanse to respond the needs of children in urban and rural areas, although it is reported that the establishment of other units is in process. Regardless, the number of units it is estimated that they need harmonization and 
integration of supporting policies in the context of protecting the rights of children at risk.

For juveniles in conflict with the law, operate the "sections of juvenile detention" and operates at full capacity "Institute the Penitentiary" in Kavaja, specifically only for this category. Employees of these facilities are trained to work with minors. (Key informant interviews: MSWY) The improvement of this service was the main focus of the activity of the General Directorate of Prisons in 2012, which has been the subject assessment report of the European Commission (2011) which mainly emphasizes on improving the health care in prisons.

Regardless, statistical data on juvenile crime compared in the years 2003, 2004, 2005, 2006, 2007, 2008 and 2009, reflect a significant increase in the phenomenon. Juveniles convicted in 2010 were 656, of whom 594 convicted of crimes and sentenced to 62 criminal offenses. Characteristic is that even in 2010, 91\% of juvenile offenders are for crimes. (Statistical Annual, edition of Ministry of Justice, 2010)

\section{Implementation of policies on young people in need}

NSSI is estimated that has influenced the new formulation of policies / programs or increased funding to reduce social exclusion. By a decision of the Council of Ministers (DCM) are approved criteria to be met by families who take children in foster care.

Child House "Zyber Hallulli" in Tirana was transformed from a centre for orphaned children-family home in small apartments. Foster Care Service is piloted in Tirana and Shkodra in 70 families. (Key informant interviews: SSS)

Targeting of different groups than those treated by both existing programs may consider that they have given "value added".

In the framework of the program "Second Chance", which is implemented by the Ministry of Education and Ministry of Social Welfare and Youth are treated children that have abandoned the school. This program has defined as objective to be accomplished within 2015, to increase the enrolment of Roma children, to draft individual plans for 
Journal of social policy, year 8, no.11/2 Skopje, November 2015

disabled children, for children on blood feud, etc. (Key informant interviews: SSS)

It is estimated that there are difficulties regarding the CPU and CRU as they are a new model even has 5 years to apply in some pilot areas, geographical distribution has not been the same in the period. Even positive will of the LGUs, limited budget remains an obstacle to the extension of the CPU \& CRU across the country.

The model of Child Labour Monitoring Unit does not apply at the regional level in Albania. For this, CPU will play an important role in identifying children working in the streets and coordinating of help in cooperation with governmental and non-governmental institutional mechanisms.

According to INSTAT analysis, preschool education has a consistent state of number of children registered in the past five years. (INSTAT/official data, 2010) However, it remains low the number of registered children due to declining fertility during the transition period. The participation rate in this level of education compared with the corresponding age group of the population is still low. INSTAT data during 2009-2010 shows that 74914 children (38 208 urban and 36706 rural) 3-5 years are enrolled in preschool education compared with 75455 (38 507 urban 36938 rural) registered during 2008-2009.

School abandonment is evident and this is more frequent in rural and suburban areas. Poverty, frequent residential movement, etc., are identified as main causes of this phenomenon.

Access to university education is still low in Albania, compared with OECD countries. Currently, the average of attendance is 11.9 years (14 years in OECD countries), which is explained by the low level of secondary education enrolment.

In Albania child care service organization is provided in three levels, primary, secondary and tertiary health services. Health-care services provided in primary health care, consist in care for the child, monitoring of child growth and development, immunization, paediatric 
and outpatient service. Primary health services are offered based on the approved package by Order of the Minister of Health. These services are provided free of charge for children.

The health situation is presented with problems due to the difficult period of transition, however, leading indicators are improving especially in the primary health service and the hospital ones. Child health is closely linked to poverty, resulting in child malnutrition, particularly in rural areas; poor hygiene services, such as potable water security and in some areas even lack the infrastructure for potable water; tendency of low breastfeeding, especially in urban areas; low education level of parents. (MSH, 2010)

Regarding access to health services, it is noted as a problem the state of the main road for transportation of patients in emergency cases to the nearest and specialized canters. Often, especially during winter in these areas, when roads become blocked from snow, the only option remains the emergency aid via helicopters. (FG in Dibër.)

Health indicators for children's primary care indicate an increase of the visit's number to clinics in general and rural areas as well. $\mathrm{MOH}$ data show that only $70 \%$ of villages are covered with health canters. In 2010 the infant mortality rate per 1000 live births has reached $11.4 \%$. (MSH, 2010).

The analysis of some infant mortality indicators show that these indicators are constantly improving, and in accordance with specific goals SKPS. Infant mortality is about $40 \%$ higher in rural areas compared to urban areas, and it is 2-3 times higher in the groups with higher education. About $40 \%$ of infant deaths occur during the first month of life and $1 / 4$ occur during the first week (QFS, 2008). In 2011, according to statistics marks 8.7 deaths per 1000 live births. (Ministry of Health/official data, 2011)

According to data obtained from PHI, 95\% - 96\% of children aged 18-29 months are fully vaccinated. Concerning coverage for specific 
vaccines, at least $97 \%$ of children have received BCG, three doses of DTP, polio, hepatitis B and measles vaccine. There is a slight decrease in the DTP vaccination by $100 \%$ for the first dose to $98 \%$ for the third dose. With these data clearly show that in Albania there is a strong vaccination program.

Albania has a "National Action Plan for Immunization" and the "Immunization Strategy for 2009-2015", which includes the new vaccine added as the Hepatitis A, rotavirus, pneumococcal, etc. Since 2005, all vaccines purchased with Albanian state funds. The above mentioned vaccination coverage has been for many years a policy to cover all regions. All vaccinations are provided in primary care centers, and registered in the national registry of immunization.

\section{Other assessed measures are:}

- About 600 doctors and 500 nurses are trained in northeastern areas of the country, Kukes, Dibra, Mat Bulqiz, Burrel, Has Fier, Korçe regarding the Integrated Management of Childhood Illnesses.

- All maternity wards personel in 36 districts on Albania are trained for counselling skills on breastfeeding.

- The child and mother health service in primary health care system are reorganized.

- Promotion and use of the model of Integrated Management of Childhood Illnesses, tracking and treatment of children 0-5 years old in child care services.

- Promotion of maternity services in district hospitals to implement the initiative of WHO / UNICEF "child friendly hospitals" about 10 steps of breastfeeding.

- Improving nutritional situation of children in northern regions areas of Albania

- Tracking and monitoring of mortality and infant and child morbidity.

- Promoting a healthy growth and development of children in rural northern community. 
- Provide vaccination of children including vulnerable groups such as Roma minorities.

- Coverage with medical personnel in rural areas.

Services provided for children at the national level are characterized by a diverse typology, with a relatively broad distribution in the country but mainly concentrated in large cities. In the following data is noted that there is a reduction in the number of residential services and growing of community services in line with the goals of NSSI. Also the number of beneficiary children in non-public social care services has a significant increase while in public the number of beneficiaries is quite small.

\begin{tabular}{|c|c|c|c|c|c|c|c|c|c|c|c|c|c|c|c|c|c|}
\hline \multirow{3}{*}{ Center } & \multicolumn{4}{|l|}{2009} & \multicolumn{3}{|c|}{2010} & \multicolumn{2}{|c|}{2011} & \multicolumn{4}{|c|}{2012} & \multicolumn{4}{|c|}{2013} \\
\hline & \multicolumn{2}{|l|}{ Public } & \multicolumn{2}{|c|}{ Non public } & \multirow[b]{2}{*}{$\mathrm{P}$} & \multirow{2}{*}{\multicolumn{2}{|c|}{ NP }} & \multirow[b]{2}{*}{$\mathrm{P}$} & \multirow{2}{*}{$\begin{array}{l}\mathrm{N} \\
\mathrm{P}\end{array}$} & \multicolumn{2}{|l|}{$\mathrm{P}$} & \multicolumn{2}{|l|}{ NP } & \multicolumn{2}{|l|}{$\mathrm{P}$} & \multicolumn{2}{|c|}{$\mathrm{NP}$} \\
\hline & Rezid & $\begin{array}{l}\text { Dail } \\
\mathrm{y}\end{array}$ & Rezid & Daily & & & & & & $\begin{array}{l}\mathrm{R} \\
\mathrm{e}\end{array}$ & $\begin{array}{l}\mathrm{Da} \\
\mathrm{i}\end{array}$ & $\begin{array}{l}\mathrm{R} \\
\mathrm{e}\end{array}$ & $\begin{array}{l}\mathrm{D} \\
\mathrm{a}\end{array}$ & $\begin{array}{l}\mathrm{R} \\
\mathrm{e}\end{array}$ & $\begin{array}{l}\mathrm{d} \\
\mathrm{a}\end{array}$ & $\begin{array}{l}\mathrm{R} \\
\mathrm{e}\end{array}$ & $\mathrm{Da}$ \\
\hline \multirow[t]{2}{*}{ Center } & \multicolumn{2}{|l|}{16} & \multicolumn{2}{|l|}{41} & 11 & \multicolumn{3}{|c|}{50} & & & & \multicolumn{2}{|l|}{45} & & & & \\
\hline & 13 & 3 & 16 & 25 & \begin{tabular}{l|l}
9 \\
\end{tabular} & 2 & & & & & & 18 & 27 & & & & \\
\hline $\begin{array}{l}\text { Total } \\
\text { child. }\end{array}$ & \multicolumn{2}{|l|}{393} & \multicolumn{2}{|l|}{2.296} & $\begin{array}{l}40 \\
0\end{array}$ & \multicolumn{2}{|c|}{ 7. } & & & \multicolumn{2}{|c|}{$\frac{1}{313}$} & \multicolumn{2}{|c|}{1958} & 342 & & \multicolumn{2}{|c|}{355} \\
\hline
\end{tabular}

Source: State Social Services

In the framework of Reform of Social Services are encouraging alternative forms of services in residential care facilities for children, namely, day services, counselling for children and their families as well as community services (MSWY, ACER, UNICEF report, 2010). In the form of 12 family houses are providing services for 223 children.

In the framework of the 'Strategy for Domestic Custody Services "shows that in the years 2010-2011 have taken custody of children every year 190 -195 Social Care Institutions, which noted that public institutions have taken into custody almost equal ratios with non-public. While 115 files are in the process of examination in court. (SSS report, 2013)

Municipalities estimates included in this assessment and have included in their structures Child protection units (CPUs), show that they 
Journal of social policy, year 8, no.11/2 Skopje, November 2015

are effective units in the identification, assessment and referral of children in need, between which and custody cases, although new.

Respondents point out that when there is a professional staff that deals only with these issues more efficiently and the work is not merely formal as occurs when there is such a structure. One of the respondents noted that "CPU services are more effective for children in need to refer cases for solutions and monitoring structures. A weak point in this regard is the lack of services for street children and not very good cooperation between stakeholders in central and local levels."

Regarding residential / day from interviews with representatives of LGUs in Berat results that currently operate two such and finances $100 \%$ one of them; some such in Korca, although services are not well-planned; Kukes day centers for children with disabilities and children in need where LGUs should take measures for their financial support and ongoing employment of professional persons; Durres has a center for autistic children; Lezha 1 center for children in need and children mainly Roma and Egyptian communities. In these centers generally provide support for children's education, sports and recreational activities and to support food aid and financial assistance for the families of these children.

In the opinion of all respondents, LGUs should be more financially support these services so that they are more stable in time and quality of professional services.

Despite legal penalties, the phenomenon of child labour in Albania is widespread. The employment of children is prohibited as long as children attend compulsory education. Street children, children with disabilities and children who are victims of blood feud face problems in terms of education. Many of them fail in the pursuit of education during the academic year. Also in terms of education lacks the inclusion of disabled children in mainstream classes.

Roma children remain contingent work in the streets and are more exposed to all forms of violence while they stay on the road. Improving 450 
economic conditions, health, education, culture, etc., for the upbringing of the child's development and registration of Roma children are considered important measures to protect them from abuse and creating opportunities for development.

The phenomenon of violence against children is widespread, as well as secret. This refers to the mentality of the Albanian family that forms a child's education is the punishment. NGOs in the field of protection of rights of children work to raise awareness of this phenomenon. The health sector has met regularly registering cases of domestic violence reported by districts. During 2011, 146 cases reported so far, of which 84 of them are children. (MoH report, 2011)

\section{FINDINGS}

Based on the policies and programs analysis and on the carried out interviews with key persons and focus groups organized, findings are as follows:

- There is no specific legislation for services for children with special needs, disabilities and mental disorders.

- Limited number of CPUs and CRU raising the LGUs plays an important role in addressing the problems of children and providing support and integration programs for categories of children in need in urban and rural areas. Until now are raised 19 CPU and $1 \mathrm{CRU}$ in different municipalities and communes and others in the process of territorial distribution, although the issue remains controversial financial resources and the limited human resources, to increase the effectiveness of the services provided.

- The system of child protection services are insufficient in identifying and providing appropriate psycho-social and socioeconomic assistance for children at risk and their families.

- Poverty, social exclusion and limited opportunities to provide income families, encourage child labour. 
- Limited employment opportunities within the country and few ways for legal migration, pushing their families to undertake risky solutions for children.

- For children with disabilities, not all conditions are met by the state for special medical treatment, for which these children need.

- State budget lacks a specific item related to health services for children.

\section{RECOMMENDATIONS}

- To improve the legislation regarding services for children with special needs and disabilities.

- To include the elimination of child labour in general policies and national programs.

- To support families with economic problems to fight poverty and social exclusion through welfare and active employment programs.

- Take measures to implement the National Action Plan to Combat Trafficking in Children.

- Provide policies that address the prevention, protection, assisted voluntary return, repatriation and reintegration of trafficked children.

- Establish multi-sectoral mechanisms to identify victims of trafficking, especially of children trafficked.

- To prevent child abuse through increasing the number of CPU and CRU in all territory of the country.

- To encourage the LGU to support child care effective services for different children in need, especially in rural areas.

- To build the professional capacities of child care services in local and regional level, also LGUs.

- To improve the quality of health care services in rural and urban areas.

- To address health and social needs of children with disabilities. 


\section{Bibliography}

Albania's National Inter-Sectorial Strategy on Social Inclusion, 2007-2013.

Criminal Code of the Republic of Albania 2011.

MIE (2009). For an European Albania; The Programme of the Governing Majority and the European Integration Government 2009-2013: presented to the Parliament of Albania, Tirana, 16.09.2009.

Law No. 10 039, dated 22.12.2008 "Legal Aid".

Ministry of Education and Sports. (2009) National Strategy for Preuniversity education 2009-2013.

Ministry of Health. (2010) Health situation and health care; Achievements and prespectives for the future, $p$. 16-18.

Ministry of Health. (2010) Country Report Overview.

UNICEF. (2010) Report "Juvenile justice in Albania. An analysis of the system of administration of juvenile justice and the situation of minors in conflict with the law in Albania".

UNICEF (2012), Evaluation Report, Albania's National Inter-Sectorial Strategy on Social Inclusion, 2007-2013.

MSWY, ACER, UNICEF. (2010) National Strategy of Social Inclusion 20072013; Progress Report 2008-2009.

State Social Services. (2013) Annual Report: On the Analysis of Implementation of the Work Programme, pg 13.

World Vision Report. (2012) "The right of children with special needs for comprehensive education".

Ombudsman. (2013), Report "The legislation and public services for street children".

Save the children study. (2014), "National survey on street children in Albania".

QFS report. (2008) Children in Albania.

State Social Services, Annual report. (2013) "Services for children in need".

WHO, Regional Office for Europe, website:

http://www.euro.who.int/aids/ctryinfo/overview/20061127_1, last accessed 2 May 2014 www.instat.gov.al

http://www.moh.gov.al/index.php?module $=2 \&$ item=87; MSH: Tregues të vdekshmërisë amëtare dhe foshnjore. 
